\title{
EuroSDR - the pan-european network for mapping agencies and academia
}

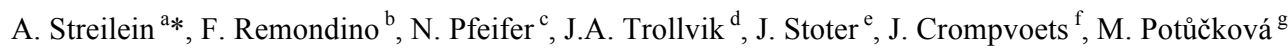 \\ a swisstopo, Wabern, Switzerland - andre.streilein@swisstopo.ch \\ ${ }^{\mathrm{b}}$ Bruno Kessler Foundation, Trento, Italy - remondino@fbk.eu \\ c Technische Universität Wien, Vienna, Austria - norbert.pfeifer@geo.tuwien.ac.at \\ ${ }^{\mathrm{d}}$ Statens Kartverk, Hønefoss, Norway - jon.arne.trollvik@kartverket.no \\ ${ }^{\text {e }}$ Delft University of Technology, Delft, The Netherlands - j.e.stoter@tudelft.nl \\ ${ }^{\mathrm{f}} \mathrm{KU}$ Leuven, Leuven, Belgium - joep.crompvoets@soc.kuleuven.be \\ ${ }^{\mathrm{g}}$ Charles University Prague, Prague, Czech Republic - mpot@natur.cuni.cz
}

SpS 12 - EuroSDR: Innovative technologies and methodologies for NMCA's

KEY WORDS: EuroSDR, network, research-based knowledge, timely research, data acquisition, modelling and processing, updating and integration, information usage, business models and operations, knowledge transfer

\begin{abstract}
:
EuroSDR (http://www.eurosdr.net/) is a non-profit organisation that provides a pan-European network that brings together mapping / cadastre agencies and academia for the purpose of applied research, and securing timely, research-based knowledge that allows the agencies to play their role as content providers and government competence centres for geographic information and spatial data infrastructures.

EuroSDR is the recognised provider of research-based knowledge to a Europe where citizens can readily benefit from geographic information. Its mission is to develop and improve methods, systems and standards for the acquisition, processing, production, maintenance, management, visualization, and dissemination of geographic reference data in support of applications and service delivery.

EuroSDR delivers advanced research-based knowledge. Its value is generated by facilitating interaction between research organisations and the public and private sector with the aim of exchanging ideas and knowledge about relevant research topics; by facilitating and contributing to research projects; and by transferring knowledge and research results to real world applications.

The paper gives an overview about EuroSDR research principles, research alliances, objectives and action plans of each of the technical commissions.
\end{abstract}

\section{INTRODUCTION}

EuroSDR can look back on a very long and successful history of 56 years. On 12 October 1953 the Organisation Européenne d'Etudes Photogrammétriques Experimentales (OEEPE) was established, “... to increase the accuracy, quality and efficiency of aerial surveys by speeding up the development and improvement of photogrammetric methods ...".

The research- and development work within the Organisation has covered all the relevant topics concerning photogrammetry during the past fifty years, including films and cameras, photogrammetric scanners, image co-ordinate measurement, aerial triangulation, digital terrain modelling as well as the manual and automated production and updating of topographic and orthophoto maps and databases.

Thus the Organisation and its members have made a significant contribution to the production of topographic maps and databases in Europe. During the past twenty years the technology has developed rapidly, with new sensors and platforms as well as the development of digital data processing. The Organisation also widened its field of activity in the late 1990 's so that it now covers, “... Research- and development of methods, systems and standards for the acquisition, processing, production, maintenance, storing, and dissemination of core geospatial data and information ...", as is recorded in the Agreement on the Formation of the European Spatial Data Research (EuroSDR) in 2003.
Today EuroSDR is a non-profit organisation that provides a pan-European network that brings together mapping / cadastre agencies and academia for the purpose of applied research, and securing timely, research-based knowledge that allows the agencies to play their role as content providers and government competence centres for geographic information and spatial data infrastructures.

This is achieved by a network of delegated from European national mapping and/or cadastral agencies and academia, who initiates and conducts corporate research projects and benchmark projects in the field of geoinfomation and their application. With this close and institutional collaboration between practice and research EuroSDR is unique in Europe.

The field of research, development and education of EuroSDR covers the whole technical field of data acquisition, modelling and processing, updating and integration, information usage, business models and operations, and knowledge transfer of geographic information. The research activities of EuroSDR are carried out through projects and workshops. These can be executed by EuroSDR alone or in collaboration with other organisations and companies.

* Corresponding author 


\section{EUROSDR VISION, MISSION AND VALUE PREPOSITION}

\subsection{Vision}

EuroSDR is the recognised provider of research-based knowledge to a Europe where citizens can readily benefit from geographic information.

\subsection{Mission}

To develop and improve methods, systems and standards for the acquisition, processing, production, maintenance, management, visualization, and dissemination of geographic reference data in support of applications and service delivery.

To be the European research platform for National Mapping and Cadastre Agencies (NMCA's), Academic Institutes, the Private Sector, Industry and User Groups, on issues related to the implementation of technology developments with respect to optimising the provision (collection, processing, storage, maintenance, visualisation, dissemination and use) of spatial information (data serving as a reference framework for organisations involved in monitoring, management and development) in a Geoinformation Infrastructure (GI) context.

\subsection{Value proposition}

EuroSDR's value is generated by facilitating interaction between research organisations and the public and private sector with the aim of exchanging ideas and knowledge about relevant research topics; by facilitating and contributing to research projects; and by transferring knowledge and research results to real world applications. The products and services offered by EuroSDR are

$\begin{array}{ll}\text { - } & \text { Network for members } \\ \text { - } & \text { Workshops } \\ \text { - } & \text { Penchmarks } \\ \text { - } & \text { Project setup facilitation } \\ \text { - } & \text { Contribution to standards } \\ \text { - } & \text { Guidelines and best practices } \\ \text { - } & \text { Education } \\ & \text { Publications (including EuroSDR web-page) }\end{array}$

\section{OPERATION}

EuroSDR aims to prioritize activities that generate researchbased knowledge that give maximum cost benefit to its stakeholders. The organization considers cooperation between mapping / cadastre agencies and academia as well as related geo-associations and industry as important elements in its operation. The strategic objectives will be achieved through the following means:

- Delegates meetings

- Workshops

- Research projects

- Publications

- Educational activities

\subsection{Delegates meetings}

The Board of Delegates consists of representatives of the EuroSDR member countries and is the supreme decisionmaking body of EuroSDR. It meets twice per year and handles scientific matters, such as the research plan, projects and results as well as other relevant scientific, technical and administrative matters, which are discussed and necessary decisions are made. It consist of keynote presentations and focussed discussions on sharing best practise and mastering new challenges. The Board of Delegates it the central medium for communication, decision and networking of the members.

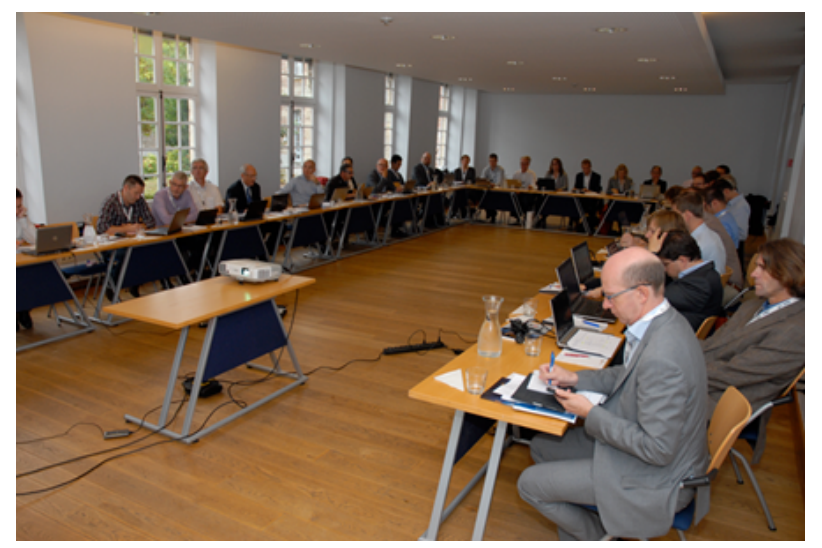

Figure 1. Board of Delegates meeting (Leuven, 2014).

\subsection{Workshops}

Workshops are dialogue-based events where real world problems, industry achievements and developments are discussed amongst experts and researchers. Workshops present the state-of-the-art in a particular field, may result in identification of research topics and may also be used for planning and dissemination of information on research activities. These workshops are documented and information is available for members.

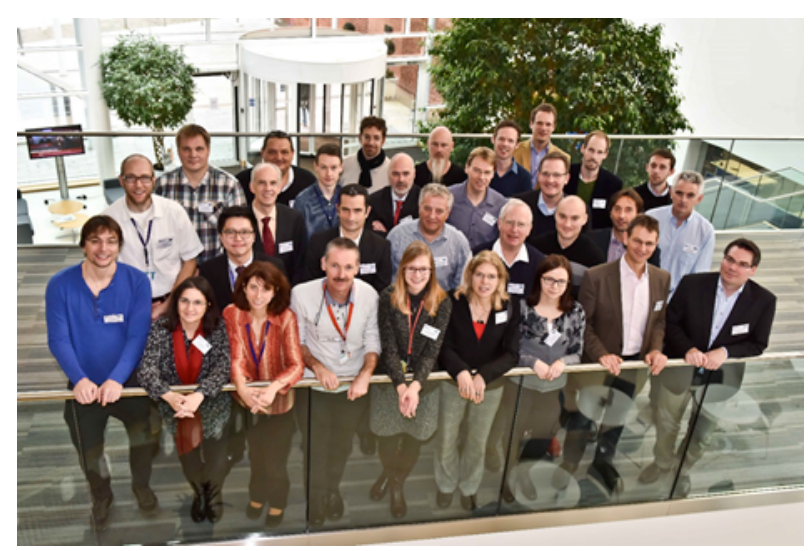

Figure 2. Eurosdr/ISPRS workshop 'Efficient capturing of 3D objects at a national level: with a focus on buildings and infrastructure', 27 - 28 november 2014 (Ordnance Survey, Southampton, UK).

\subsection{Research projects}

EuroSDR's supports especially the interaction between research organisations and the public and private sector with the aim of exchanging ideas and knowledge about relevant research topics; by facilitating and contributing to research projects; and by transferring knowledge and research results to real world applications.

The research activities are carried out through projects. The projects can be executed by EuroSDR alone or in collaboration with other organisations and companies. 
Typical research projects last for a limited time (1-3 years), are multi-site approaches with experiments using data acquired/provided by the participants, support the knowledge transfer through active participation of member and nonmember organisations and are the results are published in the official EuroSDR series.

\subsection{Publication}

The EuroSDR web-page is the prime vehicle for information dissemination from EuroSDR. Reports including results from research projects and workshops, annual reports and newsletters containing information about activities of EuroSDR are in addition published by other media, such as the official publications series of EuroSDR.

\subsection{Educational activities}

Specific E-learning courses are offered to facilitate the transfer of outcomes from EuroSDR's research activities. The educational activities will complement the research and workshop reports and address the issue of capacity building and competence development amongst stakeholders.

\section{RESEARCH}

EuroSDR delivers advanced research-based knowledge. Its value is mainly generated by facilitating interaction between research organizations and the public and private sector with the aim of exchanging ideas and knowledge about relevant research problems; by facilitating and contributing to research projects; and by transferring knowledge and research results to the production domain.

\subsection{EuroSDR Research principles}

The research activities of EuroSDR have the following principles:

- EuroSDR delivers advanced research-based knowledge.

- Research activities of EuroSDR are carried out through projects and workshops.

- Research activities address one or more of the technical fields of data acquisition, modelling and processing, updating and integration, information usage, business models and operations, or knowledge transfer of geographic information.

- Research activities are reported on the EuroSDR website and final reports of a EuroSDR project are compiled, edited and peer-reviewed in order to become an official EuroSDR publication.

- EuroSDR will provide educational activities ensuring the dissemination of the research-based knowledge gained.

- Research activities are be executed by EuroSDR alone or in collaboration with other organizations and companies.

\subsection{EuroSDR Research alliances}

To ensure a global perspective and participation EuroSDR will actively seek to intensify cooperation and collaboration with sister organisations at the European level and beyond. As such EuroSDR has active cooperations with:

- the association of the European National Mapping, Cadastre and Land Registry Authorities (EuroGeographics),

- the International Society for Photogrammetry and Remote Sensing (ISPRS),
- the International Cartographic Association,

- the International Association of Geodesy (IAG),

- the Fédération Internationale des Géomètres / International Federation of Surveyors (FIG),

- the Global Spatial Data Infrastructure Association (GSDI),

- the International Organisation for Standardisation (ISO),

- the Comitè Europèen de Normalisation / European Committee for Standardisation (CEN),

- the Open GeoSpatial Consortium (OGC),

- $\quad$ the World Wide Web Consortium (W3C),

- the European Space Agency (ESA),

- and others.

\section{EUROSDR COMMISSIONS}

The research of EuroSDR covers the whole geoinformation management cyle, ranging from the raw data acquisition to the end user of this information, with a focus on methods, systems and standards for the acquisition, processing, production, maintenance, management, visualization, and dissemination of geographic reference data.

The Commissions serve as a catalyst between the research projects and the EuroSDR network. The Commissions give a report on the relevant activities at every Board of Delegates meeting.

EuroSDR has the following six commissions:

- Commission 1: Data acquisition

- Commission 2: Modelling and Processing

- Commission 3: Updating and Integration

- Commission 4: Information Usage

- Commission 5: Business Models and Operations

- Commission 6: Knowledge Transfer

The network of the commission's work and the interaction of the commission is expressed in Figure 3.

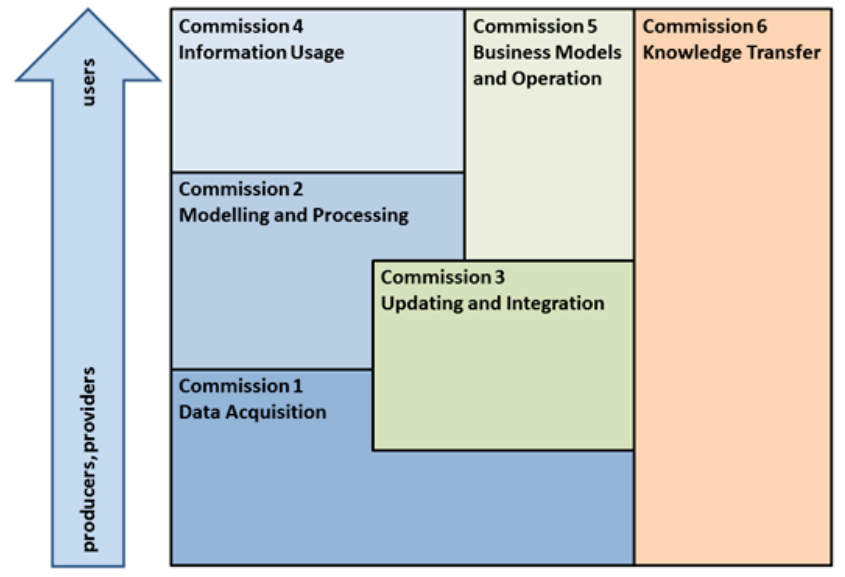

Figure 3. Network of the commission's work and interaction.

The following chapters describe the objectives and action items of each EuroSDR Commission.

\subsection{COMMISSION 1: DATA ACQUSITION}

EuroSDR Commission 1 focuses on the initial phase of the entire mapping pipeline, i.e. data acquisition. The main objective of Commission $\mathrm{I}$ is to explore, test and validate platforms, sensors and algorithms used to acquire geo-spatial data, with emphasis on accuracy, reliability and standardization of data processing procedures. The research activities of the commission therefore touch platforms and sensors (satellite, oblique and nadir cameras, RPAS, mobile mapping, etc.) as 
well as geo-referencing, matching and positioning algorithms. Some of these topics are clearly overlapping with other commissions (e.g. Commission 2 and 3) showing how commissions and activities are interlinked.

The ongoing and recently closed Commission 1 activities includes:

- EuroDAC - EuroSDR network on Digital Camera Calibration and Validation (Cramer, 2008);

- Medium Format Digital Camera (Grenzdoerffer, 2008; 2010);

- Radiometric Aspects of Digital Photogrammetric Images (Honkavaaraa et al., 2009);

- $\quad$ RPAS/UAV (Everaerts, 2009);

- Oblique aerial imagery / Multi-platform photogrammetry (Remondino and Gerke, 2015).

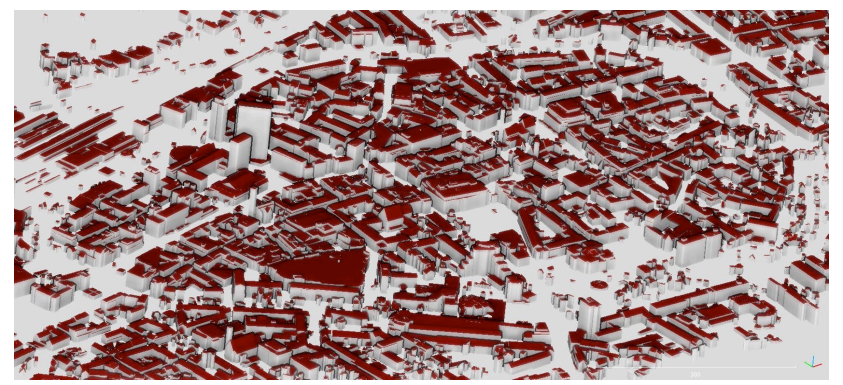

Figure 4. 3D building blocks (LOD2) automatically generated from oblique imagery.

In particular, the oblique imagery activity (Fig. 4) started in 2013 to evaluate potentials and limitations of this technology and continuously update EuroSDR members on the ongoing developments in sensors and software. Within the activity, an international workshop was held in Southampton with more than 100 participants from $\mathrm{R} \& \mathrm{D}$, companies and mapping agencies (http://www.eurosdr.net/workshops/eurosdrisprsworkshop-oblique-cameras-and-dense-image-matching).

A potential new activity under consideration deals with mapping from high-resolution satellite imagery for mapping purposes.

\subsection{COMMISSION 2: MODELLING AND PROCESSING}

Commission 2 focuses on advanced ways of modelling and processing 2D and 3D spatio-temporal data: How to structure such data which can be in any form and hence very heterogeneous and massive (i.e."big"): points clouds, object oriented data sets, at different levels of detail (i.e scale), above and underground, collected for different applications; How to maintain and update the large amount of heterogeneous data? How to process the $2 \mathrm{D} / 3 \mathrm{D}$ data and how to distribute the $2 \mathrm{D} / 3 \mathrm{D}$ spatial information via the Web?

Topics of this commission are: Data models, information models and data structures; 3D GIS, also in relation to BIM; Time; Database management systems; Multi-scale \& generalisation; big data; geoprocessing; cartography (incl. web cartography); validation of spatial data and cleaning; high density image matching; and standards.

One of the activities of this commission is the activity on data modelling and model driven implementation of data distribution (with Commission 4). NMCAs and other spatial data infrastructure (SDI) content providers are facing increasing demand for making well-documented data in known data models available as standardised web-services. National egovernment initiatives require spatial data to be modelled seamlessly with non-spatial data; INSPIRE puts requirements on GML application schemas and web-service standards; and the European Location Framework (ELF) project brings the national SDIs together in a pan-European context. Data modelling as such is a mature discipline, but how best to handle a number of specific modelling issues for geo-data is still challenging. In addition, although the potential benefits of implementing an automated data distribution environment are obvious and automated generation of GML application schemas based on UML data models is widely used (e.g. in INSPIRE context), many considerations need to be taken into account when making the data models, and automatically generating database schemas. Web-services based on UML data models add even another level of complexity. The commission aims to contribute to finding solutions to these challenges, like the workshop we organised in 2015 on this topic with relevant partners (i.e. OGC. ELF, AGILE and JRC). The workshop outcomes and materials are available via the EuroSDR website (EuroSDR, 2015).

Another main research topic is automated map generalisation, i.e. the automated extraction of a less detailed map from a highly detailed map as is the traditional task of NMAs, see Figure 5.
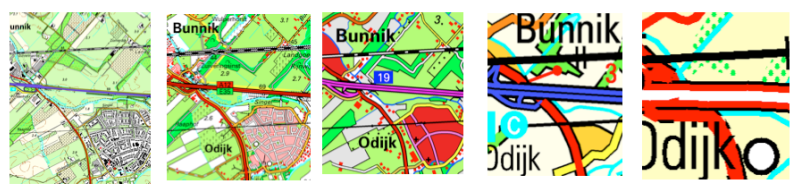

Figure 5. Map series of Netherlands' Kadaster (1:10k, 1:50k, $1: 100 \mathrm{k}, 1: 250 \mathrm{k}, 1: 500 \mathrm{k})$.

This topics significantly benefits from the close collaboration between researchers, NMAs and industry in EuroSDR. Since decades researchers have studied the complex problem of automating a process that used to be done by cartographers. Recently, there have been several automated generalisation achievements in practice, such as the automated generalisation of OS MasterMap to OS VectorMap District in Great Britain (Regnauld, 2011) and the replacement of the manual generalisation production line by a fully automated workflow at the Dutch Kadaster of the 1:50k map series (Stoter, et al, 2014). Other examples of automated generalisation solutions have been published by Duchene et all (2014). The activities of EuroSDR on multi-scale \& generalisation are often done in collaboration with the Commission on Generalisation and Multiple Representation of the International Cartographic Associations. For example, two workshop have been organised to exchange the experiences of automated generalisation within National Mapping Agencies and to identify open issues, see ICA (2013; 2015).

Another main research topic of this commission is on $3 \mathrm{D}$ mapping. Techniques for collecting, reconstructing and maintaining 3D information have matured and many applications make use of 3D data ranging from flooding and noise simulations to energy and urban heat island calculation. Consequently, there is an increasing need for up-to-date, countrywide 3D data. Several National Mapping Agencies in Europe are making the step from $2 \mathrm{D}$ to $3 \mathrm{D}$ mapping to produce such data or are considering to make this step (see Fig. 6). 


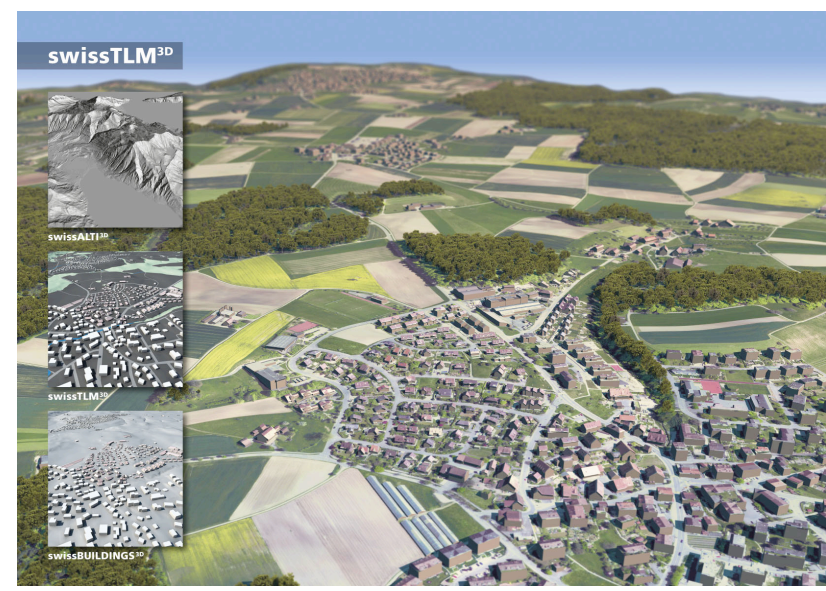

Figure 6.3D topographic landscape model created by swisstopo.

To join experiences and pursue the research agenda for $3 \mathrm{D}$ mapping, twelve European National Mapping Agencies of EuroSDR have organised themselves in a 3D Special Interest Group, i.e. EuroSDR 3D SIG (Stoter et al, 2014). The group meets two till three times a year to exchange experiences and to work on the working plan of the group. The group organises workshops on open issues like on the efficient capturing of $3 \mathrm{D}$ objects at national level in 2014.

In addition, they are developing common specifications for 3D mapping. The objective of this shared specification for $3 \mathrm{D}$ mapping is to define how objects in existing 2D map databases at NMAs could be represented geometrically in 3D. It builds on existing concepts like the Levels of Details, commonly used in CityGML (Gröger and Plümer, 2012). Another activity of the EuroSDR 3D SIG was its contribution to the Quality Interoperability Experiment (QIE) on defining and validating data quality requirements of CityGML data (OGC, 2014; Ledoux, 2014). This was a joint initiative of OGC, SIG3D and EuroSDR 3D SIG. The aim of the experiments was to formally define data quality requirements for a general CityGML data specification, to provide recommended implementation guidance for 3D data, and to provide a suite of essential quality checking tools to carry out quality assurance on CityGML data. This has been accomplished by evaluating the quality of existing CityGML data as well as of CityGML sample data sets that have been specifically developed for this experiment with different quality checking tools. The report of the QIE will be published in June, 2016.

Another ongoing activity of the EuroSDR 3D SIG, is the project on "assessing the economic value of 3D geo-information", together with EuroSDR commission 5. Despite the potentials of 3D, the NMAs in EuroSDR 3D SIG observe an underuse of the 3D data they produce. The project aims at better understanding the mismatch between the availability of $3 \mathrm{D}$ data they produce and the use of it (beyond visualisation) to be able to address this gap. The project has started early 2016 and is expected to run for one year.

The project has started with an analysis of uses cases in which $3 \mathrm{D}$ gives added value. For a selection of these use cases the value chain for NMAs will be assessed. The project is funded through "crowdfunding": eleven National Mapping Agencies (NMAs) and EuroSDR as 12th partner each contribute financially. The results of the project will give the participating NMAs understanding in the business case of 3D data: In what applications does 3D give added value? What are the required $3 \mathrm{D}$ data for these applications? What are the costs and benefits to collect and maintain these $3 \mathrm{D}$ data nationwide?
Potential new activities of the EuroSDR commission on modelling and processing are: Mapping from high-resolution satellite imagery; Exploitation and usage of cloud processing services in NMCA and a Benchmark project on high density imaging for updating 3D data products (e.g. 3D topographical data sets).

\subsection{COMMISSION 3: UPDATING AND INTEGRATION}

Commission 3 concentrates on what has been a key objective of NMCAs ever since, namely the updating of geospatial information, often based on change detection. As the production environments changed from standard data flows using one type of sensor only, i.e. the aerial photogrammetric camera, to a multitude of sources, including now LiDAR, volunteered geographic information (Mooney and Morley, 2014), geodata from terrestrial mobile platforms, and satellite imagery, the integration of different data streams became important.

Update cycles for the entire topographic information used to be in the order of 5 years, but decreased in some EuroSDR member countries to 3 or even 2 years for the entire national area. Thus, the efficiency is becoming more and more a matter of concern, and this mandates the development of automated, if not completely automatic, update procedures. A continuous update stream for authorative nation-wide data is currently available for some special classes in some countries (e.g. routable road networks, cadastral boundaries). Still, this is not typical for all classes of topographic information. Nonetheless, it demonstrates future expectations.

Having finalized "map" updating in a certain area makes the old map historic data. An organized set of time-stamped data allows monitoring processes. Thus, only structured archiving of historic data secures the value of such a record. This includes notably the archiving of metadata as well.

A key challenge in updating geospatial data and the integration of different geospatial data sets is maintenance of the quality of the data.

Commission 3 thus aspires to contribute to advanced ways of updating and integration of spatial information by investigating, demonstrating, evaluating and documenting new methods.

The ongoing and recently finalized activities of commission 3 thus include projects and workshops on:

- Updating topographic databases from images (Domenech and Mallet, 2014)

- Updating topographic databases from Lidar (ongoing)

- Preparing for Sentinel-2 data

- Using mobile LiDAR in city areas, with a concentration on the accuracy of object extraction (Lin et al., 2013)

- High density aerial image matching for DSM generation

- Laser scanning in forests

- Archiving geospatial information, published as white paper (EuroSDR, 2014)

- Understanding and using historical data

Obviously, there is some overlap with topics which are also encountered in other commissions (e.g. Commission 1, on data acquisition). In order to shed more light on the activities, information on a few projects and workshops is provided below. One workshop was held on preparations for Sentinel-2 data in Europe. Sentinel-2 is a satellite observing the Earth surface with a GSD of $10 \mathrm{~m}$ and $20 \mathrm{~m}$, resp., for bands in the visible and near and mid infrared. At the equator it has a revisit time of 10 days. With the planned constellation of 2 satellites, the revisit time will drop to 5 days and even less at higher latitudes. During the 
workshop, concerns on the orthorectification, especially for the northern European counties were raised, as well as the distribution of the massive imagery. Also the information level of NMCAs and other governmental agencies (e.g. on environment) varied considerably within Europe. On the other hand, "change alerting" has been identified as one topic of especial interest for NMCAs, which is compatible with the resolution and could probably benefit from the high revisit frequency (EuroSDR, 2014).

High density image matching was executed as a series of two consecutive benchmark projects. It included participants from industry (software vendors), academia, and mapping agencies. High resolution imagery was made available to test participants, which used their own and/or commercially available algorithms for the generation of digital surface models (Haala et al., 2013). The outcome of this workshop demonstrated the maturity of the algorithms. The method became standard in many NMCAs in the meantime.

Nation-wide generation of height data is an ongoing task within most European national mapping agencies. However, the status and requirements are quite different among the different NMA's, and therefore it is difficult to find suitable fields for cooperation. A workshop on this topic was held in January 2016, with participants from both NMA's and private companies. The main objective was to discuss different aspects about laser data and other sources used for generation of detailed height data at a national level (EuroSDR, 2016).

Finally, a benchmark project currently (2015-2016) running investigates using terrestrial laser scanning (TLS) in forests. Data was acquired with two standard configurations (1 central scan vs. 1 central and 4 peripheral scans) in more than 20 plots featuring different types of undergrowth (from none/sparse to dense), terrains shape, and tree distribution (in species, distance, maturity, etc.). First results are published (Liang et al., 2016), demonstrating the advantage of a multi-scan configuration and the high accuracy reached by TLS in retrieving DBH (tree diameter at breast height) and the stem curve, i.e. the change of the radius with tree height (see Fig. 7).

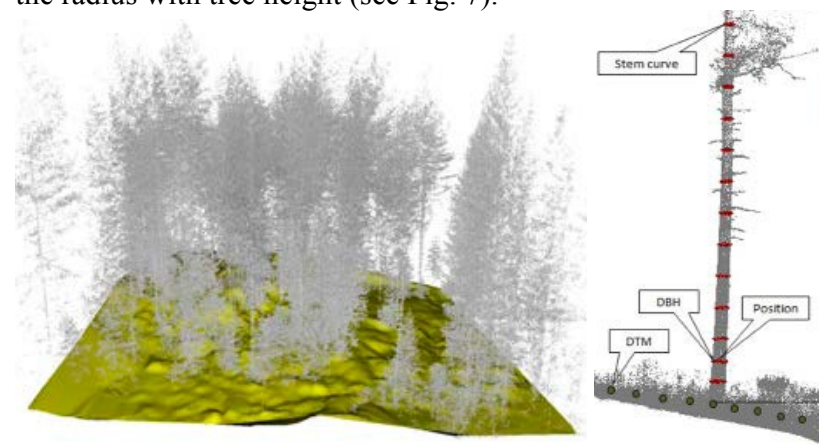

Figure 7. TLS in Forestry benchmark, Left: extracted DTM and point cloud of trees, Right: example of reference data: DTM, $\mathrm{DBH}$, tree position and stem curve (tree height not shown).

\subsection{COMMISSION 4: INFORMATION USAGE}

The mission of Commission 4 is to explore, demonstrate and contribute to further increase in access to authorized geodata, and contribute to improve the mechanisms for dissemination of geodata from database to end user. The Commission 4 also cover to investigate, evaluate and document developments in the technologies for data integration, service-level interoperability and delivery of all forms of geoinformation, data and services.

Following EuroSDR position paper on Linked data, an EuroSDR Linked Data seminar was organized by the Dutch Kadaster and IGN France in Paris in April 2015. The goal was to get more insight in the potential contributions and potential new needs brought by these new technologies to the domain of geo-referencing in the largest sense, i.e. location framework on the Web and for the Web. One of the conclusions was that there is a need to connect different European initiatives related to authoritative data with a location, and linked data (EuroSDR 2015b).

Based on outputs from the first seminar and on discussions at the following EuroSDR board of delegates meeting, the decision was made to adopt a perspective centered on the problems to be solved rather than on the technology. IGN France and Dutch Kadaster framed a new event aiming at reaching a common ground between people with different backgrounds in location framework on the web, practically Linked data believers and people attached to GI science unsolved issues. It was organized in February 2016, jointly with the meeting of the Spatial Data on the Web working group of W3C and OGC.

\subsection{COMMISSION 5: BUSINESS MODELS AND OPERATION}

This is a new commission (founded in 2015) as research issues related to the businesses become more relevant for NMCA's (see United Nations Committee of Experts on Global Geospatial Information Management, 2013). This does not mean that this topic was fully ignored in the past (see for example projects on INSPIRE (Vanden Berghe et al., 2011; De Vries et al., 2011), crowdsourcing (Mooney and Morley, 2014) and preservation of the geographic information production process.

With business models we refer to definition of Al-Debei et al. (2008): 'Abstract representation of an organization (in particular a NMCA), be it conceptual, textual, and/or graphical, of all core interrelated architectural, co-operational, and financial arrangements designed and developed by an organization presently and in the future, as well as all core products and/or services the organization offers, or will offer, based on these arrangements that are needed to achieve its strategic goals and objectives'. This definition indicates that value proposition, value architecture (the organizational infrastructure and technological architecture that allows the movement of products, services, and information), value finance (modeling information related to total cost of ownership, pricing methods, and revenue structure), and value network articulate the primary constructs or dimensions of business models (Al-Debei and Avison., 2010).

The main objective of this Commission 5 is to contribute to the development and implementation of business models describing the rationale of how NMCA's can create, deliver, and capture value, in economic, legal, social, governance, cultural or other contexts. As such, the scope of this commission is wider than the one according to the definition of Al-Debei et al. (2008). Commission 5 also takes into account issues related to governance (such as coordination structures, policy management and partnerships) and legalisation (such as privacy, liability, licensing, security, IPR) as they form key contextual factors for shaping appropriate business models.

Commission 5 has the ambition to initiate projects and workshops on topics such as: business modelling for spatial data infrastructure, Geographic information valuing, Geospatial brokering, Governance modelling for geographic information management (incl. structures, Roles, Task allocations), (Marine) spatial data infrastructure concepts and implementations, and Open data business models.

Since the foundation of Commission 5 has already co-organised a workshop 'Tutorial on Cost Benefit Analysis in the context of Geospatial Information' (Paris, 9 March) together with OECD, 
NASA and USGS, wrote a discussion paper on NMCAs' adaptations to alternative sources for the EuroGeographics General Assembly 2015 (Crompvoets et al., 2015), relaunched the second phase of the 'Crowdsourcing and National Mapping' project, and initiated projects on 'Coastal spatial data infrastructures' to seamlessly integrate marine and terrestrial data as well as 'Business models for open data of NMCA data' to review relevant business models, identify the implications for applying these business models.

\subsection{COMMISSION 6: KNOWLEDGE TRANSFER}

The main purpose of the newly established commission is to support the transfer of knowledge from EuroSDR research projects to NMCAs, academia and industry and to fulfil specific NMCAs demands for knowledge update. Its activities cover educational services and dissemination of methodologies, developed tools and research reports in the form of EuroSDR official publications and via the EuroSDR homepage. The commission works in close collaboration with the commissions 1-5 (see Figure 1).

Since 2002, EuroSDR annually offers four two-week e-learning courses combined with a two-day pre-course seminar on topics that are basically generated from the EuroSDR research projects (Fritsch et al., 2012). This fact makes the EuroSDR educational service (EduServ) unique in the sense that it reflects the newest developments in the field of geoinformation science and technology and at the same time it meets requirements of NMCAs personnel for knowledge update in this field. In average, EduServ is yearly attended by thirty participants from NMCAs, academia and industry, mostly from European countries.

As a new educational activity built on the EuroSDR network, an intensive one week residential course in gravity and height for national mapping and geodetic surveying was arranged by Dublin Institute of Technology (DIT) in spring 2015. Collaboration among specialists from DIT, the Swedish Lantmäteriet, the Dublin Institute of Advanced Studies and Ordnance Survey Ireland resulted in the design of a 5 ECTS course open to staff of NMCAs, public authorities and Master/PhD students interested in height determination and maintenance. Continuation of this new model of cooperation among EuroSDR members in education and capacity building is currently in discussion.

In order to strengthen its network in academia and especially to attract young scientist, EuroSDR has established an award for the best $\mathrm{PhD}$ thesis that has significantly contributed to the development of geoinformation science in the context of national mapping and cadastre. Starting from 2016, the awarded candidates will be invited to present their work at the autumnal board of delegates meeting.

Looking to near future, in addition to on-going activities the commission would like to establish a closer collaboration on organizing short courses or on development of e-learning materials with related associations (e.g. ISPRS, ICA, AGILE).

\section{SUMMARY}

EuroSDR is a non-profit organisation that provides a panEuropean network that brings together mapping / cadastre agencies and academia for the purpose of applied research, and securing timely, research-based knowledge that allows the agencies to play their role as content providers and government competence centres for geographic information and spatial data infrastructures.

EuroSDR is since more than 50 years a recognised provider of research-based knowledge to a Europe where citizens can readily benefit from geographic information. Its mission is to develop and improve methods, systems and standards for the acquisition, processing, production, maintenance, management, visualization, and dissemination of geographic reference data in support of applications and service delivery.

The network delivers advanced research-based knowledge. Its value is generated by facilitating interaction between research organisations and the public and private sector with the aim of exchanging ideas and knowledge about relevant research topics; by facilitating and contributing to research projects; and by transferring knowledge and research results to real world applications.

\section{ACKNOWLEDGEMENTS}

The authors would like express their gratitude to all the current and former members of the EuroSDR network for their long and sustainable contribution to the development of our domain.

\section{REFERENCES}

Al-Debei, M.M., and Avison, D., 2010: Developing a unified framework of the business model concept. European Journal of Information Systems, 19(3): 359-376

Al-Debei, M. M., El-Haddadeh, R., and Avison, D., 2008: Defining the business model in the new world of digital business. In: Proceedings of the Americas Conference on Information Systems (AMCIS), Vol. 2008, pp. 1-11

Cramer, M., 2008: The EuroSDR approach on digital airborne camera calibration and certification, Int. Archives of Photogrammetry, Remote Sensing and Spatial Information Sciences, Vol. XXXVII(B4), pp. 1753-1758

Crompvoets, J., Masser, I., Streilein, A., and Lovell, D., 2015: How should NMCAs adapt to alternative sources for NMCA data? EuroGeographics General Assembly 2015. Belgrade, 4-6 October 2015. Supporting paper, 8 pages

De Vries, W., Crompvoets, J., Stoter, J., and Vanden Berghe, I., 2011: Atlas of INSPIRE - Evaluating SDI-Development through an Inventory of INSPIRE Experiences of European National Mapping Agencies. International Journal of Spatial Data Infrastructures Research, 6: 126-144

Domenech, E., Mallet, C., 2014: Change Detection in HighResolution Land Use/Land Cover Geodatabases (at Object Level). EuroSDR Official Publication No. 64, Part D. available online: http://www.eurosdr.net/sites/default/ files/uploaded_files/eurosdr_no64_a.pdf

Duchêne C., Baella, B., Brewer, C., Burghardt, D., Buttenfield, B., Gaffuri, J., Käuferle, D., Lecordix, F., Maugeais, E., Nijhuis, R., Pla, M., Post, M., Regnauld, N., Stanislawski, L., Stoter, J., Tóth, K., Urbanke, S., van Altena V. and Wiedemann, A. 2014: Chapter Generalisation in Practice within national mapping agencies, In: Abstracting geographic information in a data rich world: methodologies and applications of map generalisation. Burghardt, Dirk, Duchene, Cécile, Mackaness and William (eds.) Springer-Verlag GmbH, 2014, pp. 329-392

Everaerts, J., 2009: NEWPLATFORMS - Unconventional Platforms (Unmanned Aircraft Systems) for Remote Sensing. EuroSDR Official Publication No 56 
EuroSDR, 2014: GI+100: Long term preservation of digital Geographic Information - 16 fundamental principles agreed by National Mapping Agencies and State Archives. White paper. Available online: http://www.eurosdr-ireland.net /archiving/GI+100\%20\%2016\%20EuroSDR\%20Archiving\%20 Principles_V3\%201.pdf

EuroSDR, 2014: Preparations for Sentinel 2 in Europe, workshop summary and recommendations. http://www.eurosdr.net/workshops/preparations-sentinel-2europe

EuroSDR, 2015a: Workshop outcomes, 'data modelling and model driven implementation of data distribution', http://www.eurosdr.net/workshops/eurosdragileogcjrcelfworkshop-'data-modelling-and-model-driven-implementationdata

EuroSDR, 2015b: NMCA's getting actively involved in Linked Data! Workshop report.

(http://www.eurosdr.net/workshops/workshop-

$\% \mathrm{E} 2 \% 80 \% 9 \mathrm{Cnm}$ cas-getting-actively-involved-linked-

data $\%$ E2\%80\%9D-workingsession-ign-paris-april-10th)

EuroSDR, 2016: Nationwide generation of height data - from Airborne laser scanning and other sources. Workshop (http://www.eurosdr.net/workshops/eurosdr-workshopnationwide-generation-height-data-airborne-laser-scanning-andother)

Fritsch, D., Mooney, K., Oestman, A., 2012. EduServ - The Education Service of EuroSDR: Sharing Experience for Capacity Building. In: The International Archives of the Photogrammetry, Remote Sensing and Spatial Information Sciences, Melbourne, Australia, Vol. XXXIX, Part B6, pp. 8790

Grenzdoerffer, G., 2008: Medium format digital cameras - a EuroSDR project. Int. Archives of Photogrammetry, Remote Sensing and Spatial Information Sciences, Vol. XXXVII(B1), pp. 1043-1049

Grenzdoerffer, G., 2010: Medium format digital cameras. EuroSDR Official Publication No 58, available at http://www.eurosdr.net/sites/default/files/uploaded_files/58.pdf

Gröger, G. and L. Plümer. 2012: "CityGML - Interoperable semantic 3D city models." Isprs Journal of Photogrammetry and Remote Sensing 71(0): 12-33

Haala, N., Rothermel, M., Pfeifer, N. 2013: Benchmarking Image-based DSM Generation. GIM International, Dec. 2013, pp $27-29$

Honkavaaraa, E., Arbiol, R., Markelin, L., Martinez, L., Cramer, M., Korpela, I., Bovet, S., Thom, C., Chandelier, L., Ilves, R., Klonus, S., Reulke, R., Marshal, P., Tabor, M., Scläpfer, D., Veje, N., 2009: Status report of the EuroSDR project "Radiometric aspects of digital photogrammetric airborne images". Int. Archives of Photogrammetry, Remote Sensing and Spatial Information Sciences, Vol. XXXVIII-1-47/W5

ICA, 2013: $1^{\text {st }}$ ICA / EuroSDR NMA Symposium on Designing MRDB and multi-scale DCMs: Sharing experiences between mapping agencies and the outside world. http://generalisation.icaci.org/index.php/prevevents/11-

previous-events-details/73-nma-symposium-2013-presentations
ICA, 2015: 2nd ICA / EuroSDR NMA Symposium on Designing MRDB and multi-scale DCMs: Sharing experiences between mapping agencies and the outside world http://generalisation.icaci.org/index.php/prevevents/11previous-events-details/88-nma-symposium-2015-general

Ledoux, H., 2014: Three-dimensional primitives in the contextof the CityGML QIE. https://github.com/tudelftgist/CityGML-QIE-

3Dvalidation/blob/master/solid_definition/qie_geom.pdf?raw $=$ tr ue

Liang, X., Hyyppä, J., Kaartinen, H., Pfeifer, N, 2016: Terrestrial Laser Scanning in Forest Inventories - Towards International Benchmarks. GIM International, Feb. 2016, pp 2629

Mooney, P., Morley, J., 2014: Crowdsourcing in National Mapping. EuroSDR Official Publication No. 64, Part D. available online: http://www.eurosdr.net/sites/ default/files/uploaded_files/eurosdr_no64_d.pdf

OGC, 2014: Announcement of QIE CityGML, http://www.opengeospatial.org/pressroom/pressreleases/2054

Regnauld, N. 2011: OS Vectormap District: Automated Generalisation, Text Placement and Conflation in Support of Making Pubic Data Public. In 25th International Cartographic Conference, July 2011, Paris

Remondino, F., Gerke, M., 2015: Oblique aerial imagery - A review. Proc. Photogrammetric Week 2015, pp.75-83

Stoter, J., Roensdorf, C., Home, R., Capstick, D., Streilein, A., Kellenberger, T., Bayers, E., Kane, P., Dorsch, J., Wozniak, P., Lysell, G., Lithen, T., Bucher, B., Paparoditis, N. and Ilves, R. 2014: 3D modelling with national coverage bridging the gap between research and practice. 9th International 3DGeoInfo 2014, November 2014

Stoter, J., Post, M., van Altena, V., Nijhuis, R., \& Bruns, B., 2014: Fully automated generalization of a 1:50k map from $1: 10 \mathrm{k}$ data. Cartography and Geographic Information Science, 41(1), 1-13. http://doi.org/10.1080/15230406.2013.824637

United Nations Committee of Experts on Global Geospatial Information Management, 2013: UN-GGIM: Future trends in geospatial information management: the five to ten year vision. Ordnance Survey, 40 pages

Vanden Berghe, I., Crompvoets, J., de Vries, W., and Stoter, J., 2011: Atlas of INSPIRE Implementation Methods. In: EuroSDR Official Publication No. 59. Gopher, Amsterdam, pp. 255-292 